Claude A. Trépanier MD FRCPC, Liette Isabel MD FRCPC

\title{
Perioperative gastric aspiration increases postoperative nausea and vomiting in outpatients
}

The efficacy of aspiration of gastric contents to reduce postoperative nausea and vomiting was investigated in a controlled randomized, double-blind study of 265 outpatients. Patients in the treated group had their stomachs aspirated with an orogastric tube. In the control group no tube was inserted. Data on the incidence of nausea and vomiting were collected in the recovery room, the day surgery unit and the day after surgery. The overall incidence of postoperative nausea and vomiting was comparable in the two groups. It was also comparable in the recovery room and the day surgery unit. However, treated patients had a higher incidence of both nausea (26.5\% vs $12.0 \%$, $P<0.005)$ and vomiting $(16.7 \%$ vs $6.8 \%, P<0.02)$ after their discharge from the day surgery unit. We conclude that aspiration of gastric contents with an orogastric tube does not decrease pastoperative nausea and vomiting in outpatients and may increase it after discharge of the patient.

L'efficacité de l'aspiration du contenu gastrique dans le but de réduire lincidence des nausées et des vomissements postopératoires a été évaluée au cours d'une étude contrôlée randomisée à double insu chez 265 patients dans un centre de chirurgie d'un jour. L'estomac des patients du groupe traité a été aspiré avec une sonde gastrique alors que dans le groupe témoin on n'a pas inséré de sonde. Les données concernant lincidence des nausées et des vomissements ont été recueillies à la salle de réveil, à l'unité de chirurgie d'un jour et le lendemain de la chirurgie. Lincidence totale des nausées et vo-

\section{Key words}

ANAESTHESIA: outpatients;

VOMITING: nausea.

From the Département d'Anesthésie, Hôpital de l'Enfant-Jésus Université Laval, 1401, $18^{\mathrm{e}}$ rue, Québec.

Address correspondence to: Dr Claude Trépanier, Hôpital de l'Enfant-Jésus, 1401, $18^{\mathrm{e}}$ rue, Québec, G1J $1 Z 4$.

Presented at the Canadian Anaesthetists' Society meeting, Quebec, Canada, June 1991.

Accepted for publication 11th December, 1992. missements fut comparable dans les deux groupes. Il n'y a pas eu non plus de différence à la salle de réveil et à liunité de chirurgie d'un jour. Cependant, les patients traités ont présenté une incidence plus élevée de nausées $(26,5 \%$ vs $12,0 \%, P<$ $0,005)$ et vomissements $(16.7 \%$ vs $6,8 \%, P<0,02)$ après leur départ de l'unité de chirurgie d'un jour. Nous concluons que l'aspiration du contenu gastrique ne diminue pas lincidence des nausées et vomissements postopératoires chez les patients de chirurgie d'un jour. En réalité, cette manoeuvre semble augmenter lincidence de cette complication après le départ de l'unité chirurgicale.

Nausea and vomiting are two of the most frequent and troublesome complications of general anaesthesia. Despite improvement of anaesthetic techniques and the availability of new agents, the reported incidence of nausea and vomiting remains around $30 \% .^{1,2}$ This complication is particularly annoying in the outpatient setting where the patient is expected to recover autonomy rapidly. Two studies reported that vomiting was the most frequent anaesthetic complication resulting in an unexpected hospital stay after outpatient surgery. 3,4 Many attempts have been made to prevent postoperative nausea and vomiting. One of them is to empty the stomach with a gastric tube. Although it has been recommended in review articles, ${ }^{1,5}$ most data on this topic comes from older retrospective studies. ${ }^{6-9}$ No study has investigated the effectiveness of this manoeuvre to reduce postoperative nausea and vomiting in outpatients. The purpose of this study was to investigate the effect of gastric emptying with an orogastric tube on the incidence of nausea and vomiting after general anaesthesia in outpatients.

\section{Method}

Two hundred and sixty-five ASA I, II and III patients scheduled to undergo day surgery requiring general anaesthesia were studied prospectively. Patients with upper digestive tract pathology or taking antiemetic drugs were excluded. Those scheduled for a laparoscopy were 
also excluded because it was considered unethical not to decompress the stomach prior to abdominal puncture. The protocol was approved by the hospital ethics committee and an informed, written consent was obtained from all patients. Patients were fasted from midnight and were not given any premedication. Anaesthesia was induced with fentanyl $2 \mu \mathrm{g} \cdot \mathrm{kg}^{-1}$ and thiopentone 3-5 $\mathrm{mg} \cdot \mathrm{kg}^{-1}$. Succinylcholine $1.5 \mathrm{mg} \cdot \mathrm{kg}^{-1}$ preceded by $\mathrm{d}$ tubocurarine $0.05 \mathrm{mg} \cdot \mathrm{kg}^{-1}$ was given to facilitate tracheal intubation. The lungs were ventilated by mask until complete relaxation was obtained while avoiding excessive positive airway pressure and the trachea was intubated when complete relaxation was obtained. If, during mask ventilation, the high airway pressure alarm, which was set at $25 \mathrm{~cm} \mathrm{H}_{2} \mathrm{O}$, was activated, the patient was excluded from the study. Ventilation was controlled with an $\mathrm{Oh}$ meda 7810 ventilator and a circle circuit. Minute ventilation was adjusted to maintain a normal end-tidal $\mathrm{PCO}_{2}$. Patients were then divided into two groups by random allocation. In Group 1, the study group, an orogastric tube was inserted and the stomach contents were aspirated. In Group 2, the control group, no gastric tube was inserted. Anaesthesia was maintained with $60 \%$ nitrous oxide in oxygen, isoflurane and supplemental doses of fentanyl, up to $5 \mu \mathrm{g} \cdot \mathrm{kg}^{-1}$. At the end of surgery, in the patients of the study group, the gastric tube was aspirated again and then removed and, in all patients, the trachea was extubated. Patients were then taken to the recovery room where data on the occurrence of nausea, retching or vomiting were collected. Data were collected by a nurse who was unaware of the purpose of the study and of the patient's group. Vomiting was defined as the forceful expulsion of even a small amount of gastric content through the mouth, retching as expulsive efforts not leading to the expulsion of any material and nausea as the subjective sensation of the desire to vomit. For data analysis, patients presenting with retching were considered to have vomited. The same data were also collected at the day surgery unit and $24 \mathrm{hr}$ postoperatively by telephone, also in a double-blind manner.

Sample size was calculated considering a treatment effect of $50 \%$ as minimal relevant difference, 0.10 as the upper limit for type II error and an incidence of $35 \%$ of nausea and vomiting as determined by a pilot study. Statistical analysis was done using the Chi square test with Yates correction and the Student's $t$ test, relative risks with $95 \%$ confidence interval are also reported. A $P$ value $<0.05$ was considered significant. Results are presented as mean $\pm \mathrm{SD}$.

\section{Results}

A total of 279 patients were entered into the study, 140 in the study group, 139 in the control group. Fourteen
TABLE Demographic data and data on anaesthetic doses and type of surgery

\begin{tabular}{lcl}
\hline & Treated & Control \\
\hline Number $(n)$ & 132 & 133 \\
Age $(\mathrm{yr})$ & $39.1 \pm 15.8$ & $37.6 \pm 15.5$ \\
Weight $(\mathrm{kg})$ & $70.3 \pm 17.6$ & $67.5 \pm 15.3$ \\
Height $(\mathrm{cm})$ & $166.3 \pm 22.6$ & $164.6 \pm 22.5$ \\
Duration of anaesthesia (min) & $63.6 \pm 34$ & $68 \pm 34.8$ \\
Postoperative analgesics $(n)$ & 24 & 21 \\
Sex $(n)$ & & \\
- Male & 56 & 49 \\
- Female & 76 & 84 \\
History of postoperative & & \\
$\quad$ nausea and vomiting $(n)$ & 16 & 19 \\
History of motion sickness $(n)$ & 14 & 7 \\
Mean concentration of end-tidal & & \\
$\quad$ isoflurane (\%) & $0.88 \pm 0.36$ & $0.92 \pm 0.38$ \\
Fentanyl dose $(\mu \mathrm{g})$ & $125 \pm 55$ & $125 \pm 50$ \\
Type of surgery $(n)$ & & \\
- Orthopaedic & 67 & 60 \\
- ENT & 18 & 21 \\
- Ophthalmology & 15 & 17 \\
- General & 13 & 19 \\
- Others & 19 & 16 \\
Position during surgery $(n)$ & & \\
- Supine & 122 & 124 \\
- Others & 10 & 8 \\
\hline
\end{tabular}

Mean $\pm \mathrm{SD}$ (or numbers).

No difference between the two groups for any variable.

patients were excluded because they could not be reached by phone for postoperative data collection, six in the control group and eight in the study group. Demographic data and data from surgery and anaesthesia are presented in the Table. There was no difference between the two groups with respect to age, sex, body weight, ASA physical status, type and duration of surgery, amount of anaesthetic agents received and position of the patient during the procedure. The two groups were also comparable for the presence of a history of previous postoperative nausea and vomiting or motion sickness.

There was no difference between the two groups for the overall incidence of both nausea (36.3\% vs $41.7 \%$ ) and vomiting (22\% vs $28.8 \%$ ) (Figures 1 and 2). Nausea and vomiting were also similar in the two groups in the recovery room and the day surgery unit. However, when patients were interviewed one day later, the incidences of nausea (12\% vs $26.5 \%, P<0.005)$ and vomiting $(6.8 \%$ vs $16.7 \%, P<0.02)$ after their discharge from the day surgery unit were higher in the patients whose stomachs had been aspirated. The relative risk of treated patients to suffer these complications after their release from the day surgery unit was $2.2(95 \%$ confidence interval $=1.28$, 3.78 ) for nausea and $2.24(1.06,4.74)$ for vomiting compared with untreated patients. 


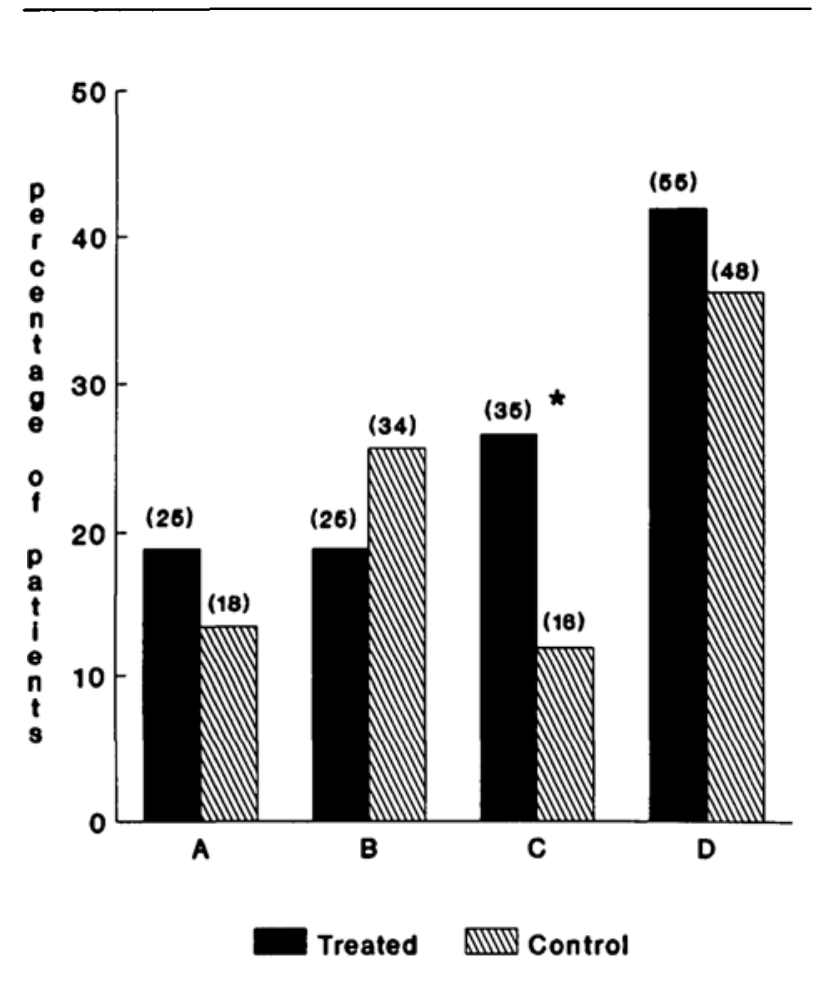

FIGURE 1 The percentage of patients in the two groups who suffered nausea. Actual number of patients who suffered nausea are shown in parentheses. $\mathrm{A}=$ recovery room; $\mathrm{B}=$ day surgery unit; $\mathrm{C}=$ after discharge from the day surgery unit; $\mathrm{D}=$ overall. $n=132$ treated group, 133 control group. $* P<0.01$.

\section{Discussion}

The use of a gastric tube to decompress the stomach is generally believed by anaesthetists to be an effective way of decreasing postoperative nausea and vomiting. This belief has made its way into review articles ${ }^{1,5}$ and textbooks ${ }^{10}$ although in the only study that has addressed the issue in a controlled manner, Hovorka et al. found that gastric aspiration did not decrease postoperative nausea and vomiting in inpatients. " Older studies which did not specifically study this variable show conflicting results, some showing a beneficial effect, ${ }^{6,7}$ while others reported either no effect ${ }^{8,11}$ or even a deleterious one. ${ }^{9}$ Our results show that aspiration of stomach contents does not decrease the incidence of postoperative nausea and vomiting found in outpatients. Moreover, patients whose stomachs were aspirated have more than twice the incidence of nausea and vomiting found in the control group after their discharge from the day surgery unit. This increase might be the result of trauma to the upper digestive tract caused by insertion of the tube. Mucosal trauma may lead to increased afferent input from the gut to the cerebral vomiting centre. ${ }^{1}$ This might become

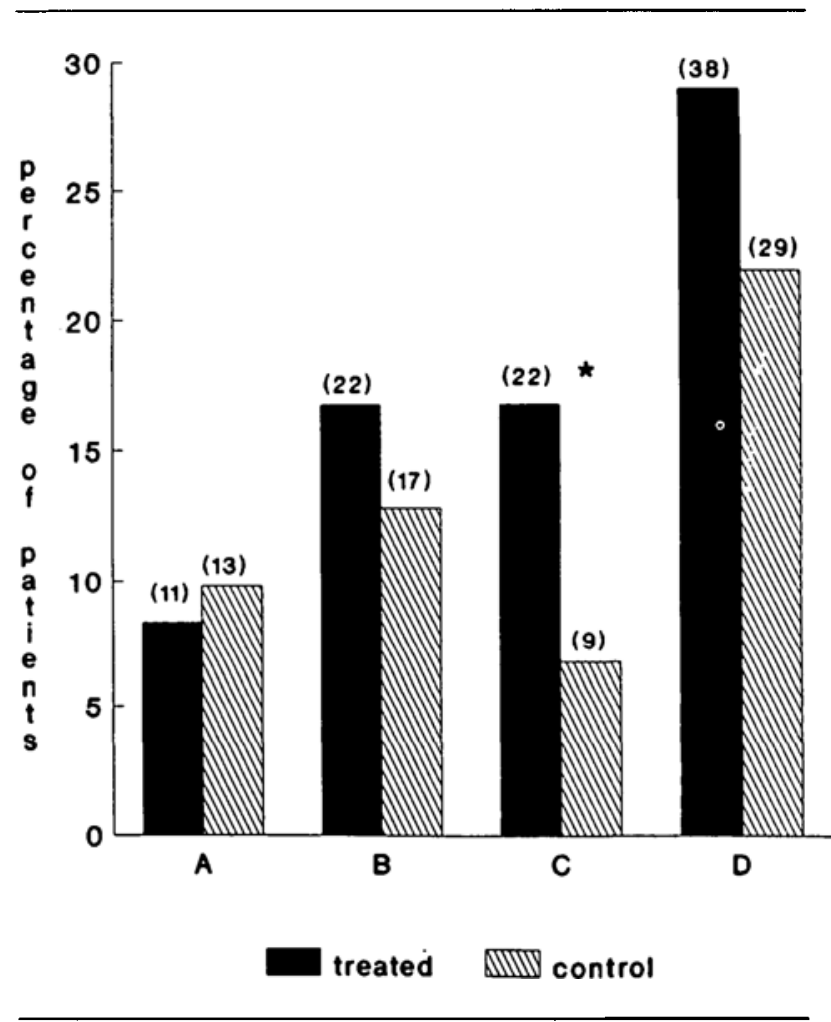

FIGURE 2 The percentage of patients in the two groups who vomited. Number of patients who vomited are shown in parentheses. $A=$ recovery room; $B=$ day surgery unit; $C=$ after discharge from the day surgery unit; $\mathrm{D}=$ overall. $n=132$ treated group; 133 control group. ${ }^{*} P<0.05$.

evident only after discharge from the day surgery unit when the effects of general anaesthesia have subsided and patients begin moving and feeding. In fact, $47.6 \%$ of the treated patients who had symptoms after their discharge from the day surgery unit had not suffered any nausea or vomiting while they were in the hospital. Thus, most of the increase found after discharge appears to be caused by delayed symptoms in previously asymptomatic patients more than by persisting symptoms in patients who had been sick in the hospital. This delayed increase is worrisome, because it occurs at a time when outpatients are assumed to have recovered autonomy.

Many factors have been implicated as causes of postoperative nausea and vomiting. We tried to control either by a standard anaesthetic technique or randomization the following variables which have been reported as possible risk factors: type of surgery, ${ }^{7,8}$ age, ${ }^{12}$ sex, ${ }^{6,13}$ anaesthetic drugs, ${ }^{1,14}$ premedication. ${ }^{15}$ The distribution of these variables was similar in the two groups. This study design allowed isolation of the effect of the insertion of the gastric tube and aspiration of the gastric content on the occurrence of nausea and vomiting. 
It is difficult to compare our data with those of Hovorka et al. "They found that gastric aspiration changed neither the overall incidence of nausea and vomiting nor the incidence at any stage of the first twenty-four hours postoperative period. However, they studied female inpatients who had had a hysterectomy and received narcotics both for premedication and postoperative analgesia. All these factors resulted in an incidence of nausea and vomiting higher than $70 \%$, more than twice the incidence that we found. This combination of multiple risk factors in the population of Hovorka $\mathrm{et} \mathrm{al}$. possibly made it more difficult to isolate the effect of gastric aspiration. Another more probable explanation for the different results of the two studies is the different study design. In Hovorka's study all the patients had a tube inserted in their stomachs but only in half of them were the gastric contents aspirated. In this study, only the patients in the study group had a tube inserted in their stomachs. The consequence of this difference in study design is that Hovorka et al. studied the effect of gastric aspiration per se while this study investigated the combined effect of the tube insertion and aspiration. Our results suggest that from the standpoint of nausea and vomiting, the deleterious effect of mucosal trauma caused by tube insertion might outweigh the hypothetical benefit of gastric content aspiration. These conclusions might not be applicable to patients whose stomachs are inflated during mask ventilation. Patients who had received ventilation by mask with an airway pressure $>25 \mathrm{~cm} \mathrm{H}_{2} \mathrm{O}$ were excluded from the study. This subgroup most likely had some degree of gastric distension and gastric aspiration and probably had more chance of a beneficial effect under these circumstances.

In conclusion, aspiration of gastric contents with a tube does not decrease postoperative nausea and vomiting in outpatients. Patients who receive this treatment had a higher incidence of nausea and vomiting after their discharge from the day surgery unit.

\section{Acknowledgements}

The authors thank all the members of their department for their collaboration and Mrs. Lyne Godin for her assistance in preparing the manuscript.

\section{References}

1 Palazzo MGA, Strunin L. Anaesthesia and emesis.

I. Etiology. Can Anaesth Soc J 1984; 31: 178-87.

2 Palazzo MGA, Strunin L. Anaesthesia and emesis.

II. Prevention and management. Can Anaesth Soc J 1984; 31: 407-15.

3 Meridy $H W$. Criteria for selection of ambulatory surgical patients and guidelines for anesthetic management: a retrospective study of 1553 cases. Anesth Analg 1982; 61: 921-6.
4 Gold BS, Kitz DS, Lecky JH, Neuhaus JM. Unanticipated admission to the hospital following ambulatory surgery. JAMA 1989; 262: 3008-10.

5 White $P F$, Shafer $A$. Nausea and vomiting: causes and prophylaxis. Seminars in Anesthesia 1987; 6: 300-8.

6 Burtles $R$, Peckett BW. Postoperative vomiting. Some factors affecting its incidence. Br J Anaesth 1957; 29: 114-23.

7 Smessaert A, Schehr CA, Artusio JF Jr. Nausea and vomiting in the immediate postanesthetic period. JAMA 1959; 170: 2072-6.

8 Dent SJ, Ramachandra V, Stephen CR. Postoperative vomiting: incidence, analysis, and therapeutic measures in 3000 patients. Anesthesiology 1955; 16: 564-72.

9 Holmes CM. Post-operative vomiting after ether/air anaesthesia. Anaesthesia 1965; 20: 199-206.

10 Cotter $J$. Complications of recovery from anesthesia. In: Hazards and Complications of Anaesthesia. London: Churchill Livingstone, 1987: 294-310.

11 Hovorka J, Korttila K, Erkola O. Gastric aspiration at the end of anaesthesia does not decrease postoperative nausea and vomiting. Anaesth Intensive Care 1990; 18: 58-61.

12 Knapp MR, Beecher HK. Postanaesthetic nausea, vomiting, and retching. Evaluation of the antiemitic drugs dimenhydrinate (dramamine), chlorpromazine, and pentobarbital sodium. JAMA 1956; 160: 376-85.

13 Bellville JW, Bross IDJ, Howland WS. Postoperative nausea and vomiting. IV: Factors related to postoperative nausea and vomiting. Anesthesiology 1960; 21: 186-93.

14 Riding $J E$. The prevention of postoperative vomiting. $\mathrm{Br} \mathrm{J}$ Anaesth 1963; 35: 180-8.

15 Nelson PS, Streisand JB, Mulder SM, Pace NL, Stanley $T H$. Comparison of oral transmucosal fentanyl citrate and an oral solution of meperidine, diazepam, and atropine for premedication in children. Anesthesiology 1989; 70: 616-21. 